\title{
Effect of Copper and Silicon Carbide Content on the Corrosion Resistance of Al-Mg Alloys in Acidic and Alkaline Solutions
}

\author{
Ahmad T. Mayyas ${ }^{1, *}$, Mohammad M. Hamasha², Abdalla Alrashdan², Adel M. Hassan², \\ Mohammed T. Hayajneh ${ }^{2}$ \\ ${ }^{1}$ Department of Automotive Engineering, Clemson University-International Center for \\ Automotive Research (CU-ICAR), 4 Research Drive, Greenville, South Carolina 29607 USA. \\ ${ }^{2}$ Center for Autonomous Solar Power, State University of New York at Binghamton, \\ Binghamton, NY 13850, USA \\ ${ }^{3}$ Department of Industrial Engineering, Faculty of Engineering, Jordan University of Science \\ and Technology, P.O. Box 3030, Irbid, 22110, Jordan \\ *Corresponding Author: ahmadm@g.clemson.edu
}

\begin{abstract}
In this study, corrosion resistance of cast aluminum based alloys and composites reinforced with silicon carbide has been investigated. Different Al-Mg-Cu alloys and Al-4wt.\%Mg-Cu/SiC composites reinforced with 5 or $10 \mathrm{vol} . \%$ SiC were subjected to corrosive media (acidic: $1.0 \mathrm{M}$ $\mathrm{HCl}$ and alkaline: 1.0M NaOH) using weight loss method to evaluate their corrosion resistance. The results show that introducing copper and silicon carbide have a negative effect on the corrosion resistance of monolithic aluminum; however, Al-based composites still being attractive materials to replace steel parts in automotive and aircraft industries and hence
\end{abstract}


studying their corrosion resistance is of high importance. Scanning electron microscopy (SEM) and Energy-dispersive X-ray (EDS) were used to show the degree of attack and of acidic and alkaline solution on the surface of the investigated materials.

Keywords: Casting; Corrosion Testing; Metal Matrix Composites; Surface Engineering.

\section{INTRODUCTION}

Aluminum matrix composites (AMCs) refer to the class of light weight high performance aluminum centric material systems. The reinforcement in AMCs could be in the form of continuous/discontinuous fibers, whisker or particulates [1], in volume fractions ranging from a few percent to $60 \%$. Studying corrosion resistance of Al-based materials is important especially for automotive and aircraft applications where the parts are prone to corrosive media like salt water solutions, acidic and alkaline media. Aluminum based composites are usually reinforced by $\mathrm{Al}_{2} \mathrm{O}_{3}, \mathrm{SiC}$, and $\mathrm{C}$. The major advantages of AMCs compared to unreinforced materials are as follows: greater strength, improved stiffness, reduced density, good corrosion resistance, improved high temperature properties, controlled thermal expansion coefficient, thermal/heat management, improved wear resistance and improved damping capabilities [1-6]. Nowadays, the increased demand for light weight components, primarily driven by the need to reduce energy consumption in a variety of societal and structural components, has led to an increase in the use of aluminum. Among the various methods to fabricate metal matrix composites, stir casting method has drawn keen attraction among the researchers due to its industrial feasibility.

The major limitation in many cases in fabricating metal matrix composites by liquid phase route resides upon the incompatibility of the reinforcement and the matrix [1-3]. This problem in case of Al-based metal matrix composite is due to the formation of stable tenacious oxide film, resulting in poor wettability with the ceramic particle. One of the common practices to improve wettability of an $\mathrm{Al}$ melt is through addition of small amount of reactive metals like magnesium and titanium prior to the incorporation of ceramic particle [1,3]. However, in the present work, 4 wt\% $\mathrm{Mg}$ was added to $\mathrm{Al}$ to improve wettability and argon flux was used during melting and pouring tasks to reduce oxidation effect. 
Corrosion is the dissolution of a metal into an aqueous environment where the metal atoms dissolve as ions. Since corrosion is always a function of the environmental conditions, control in many cases is important in order to prevent the contact between metal and the surrounding environment. The resistance of aluminum against corrosion in aqueous media can be attributed to a rapidly formed surface oxide film [4]. Therefore, aluminum has been known to exhibit widely different electrochemical properties in different aqueous electrolytes [5]. Many researchers studied pitting corrosion of aluminum alloys and aluminum composites since it is the dominant corrosion type for these materials [e.g. 5-7]. Other researchers studied behavior of aluminum and aluminum alloys under different acidic and alkaline solutions [e.g. 7-9]. Candan and Bilgic [1012] are among other researchers who studied pitting corrosion of Al-based composites in different corrosive media. Their studies not only prove that Al-SiC composites are good corrosion resistance materials, but also show that intermetallics resulted from the reaction between $\mathrm{Al}$ and $\mathrm{SiC}$ particle has a beneficial effect on corrosion resistance of the composites due to interruption of the continuity of the metal matrix [12].

Other studies of corrosion resistance of aluminum materials are focusing on the methods and materials that can help in improving corrosion resistance of such materials. Using inhibitors and protective layers to improve corrosion resistance of aluminum have been investigated thoroughly. For example, the effect of inhibitors and accelerators on the reaction kinetics of corrodent solutions was studied by Abiola et al. [13] who examined the effect of mercaptoacetic acid (MCA), on the corrosion behaviors of aluminum alloy in hydrochloric acid solutions. They found that mercaptoacetic acid acts as corrosion accelerator of aluminum in $\mathrm{HCl}$ solutions. The accelerating action of mercaptoacetic acid on aluminum corrosion is ascribed to a catalytic effect on the hydrogen evolution reaction. Oguzie et al. [14] studied the effect of addition methylene blue (MB) dye on the electrochemical corrosion of aluminum in $\mathrm{HCl}$ solutions using gravimetric techniques at 303 and $333 \mathrm{~K}$. The results indicate that MB acts as an inhibitor in the acidic corrodent. They also estimated the reaction rates and activation energies for different solutions with and without inhibitors. Lunarska and Chernyayeva [15] studied the corrosion rate, hydrogen permeation rate (hydrogen uptake) and stress corrosion cracking of $\mathrm{Al}$ in $\mathrm{NaOH}$ solutions, pure and with the addition of $\mathrm{H}_{3} \mathrm{BO}_{3}$, EDTA, $\mathrm{KMnO}_{4}$ and $\mathrm{As}_{2} \mathrm{O}_{3}$. These chemicals known as the corrosion inhibitors of $\mathrm{Al}$ in alkaline solutions [15] or as the hydrogen ingress promoter in 
electrolyte and the implantation of $\mathrm{Al}$ surface with $\mathrm{B}+$ ions inhibited corrosion. Hydrogen uptake was found to be promoted or inhibited by means of studied species, depending on the method of their introduction into the base solution and on the applied polarization.

The different studies dealt with the effect of alloying elements on the corrosion resistance of aluminum showed that magnesium tends to enhance corrosion resistance of aluminum while copper has adverse effect on the corrosion resistance of aluminum [16-18]. It was proposed that the concentrations of alloying elements, particularly copper, in Al solid solution are the key factors which could influence the pitting corrosion. Such increase of copper in the aluminum matrix increases the corrosion potential of aluminum matrix [16].

The present study is an attempt to investigate the corrosion behavior of Al-based alloys and composites reinforced with $\mathrm{SiC}$ under chemical attacks of acidic and alkaline aqueous media. In this study, two different aqueous solutions were used; namely: $1.0 \mathrm{M} \mathrm{HCl}$ as acidic environment and $1.0 \mathrm{M} \mathrm{NaOH}$ as alkaline environment. Such kind of corrosive media might be similar to what automotive and airplane parts face in their service lifetime.

\section{EXPERIMENTAL SETUP AND PROCEDURE}

\subsection{Materials}

The test materials studied in this work were a mixture of aluminum (commercial grade Al, $99 \%$ purity) and copper granules with an average particle size of $0.425 \mathrm{~mm}$ and $\sim 97 \%$ purity as a metal matrix. Silicon carbide particles ware added as reinforcement to the metal matrix. About $1000 \mathrm{~g}$ of commercial grade $\mathrm{Al}$ ingots and different weight percentages of copper powder $(0,1$, 2, 3, 4, and 5 wt.\%) were used to prepare the base metal matrix by stir casting method. Specific quantities of silicon carbide powder with an average particle size of $75 \mu \mathrm{m}$ and purity exceeds $99.5 \%$ of 5 and $10 \mathrm{vol}$ \% were added to the matrix alloy. Magnesium ingots ( 99\% purity) was added in small quantities (fixed weight percentage 4wt.\%) to promote wettability between metal matrix and reinforcement particles $[2,10]$. 


\subsection{Processing}

The synthesis of the particulate metal matrix composites used in the present study was carried out by the stir casting method (compocasting method). Aluminum ingots and copper granules melted together at $850{ }^{\circ} \mathrm{C}$. The amount of $\mathrm{SiC}$ powder pre-oxidized at $900^{\circ} \mathrm{C}$ for about 30 minutes to form a layer of $\mathrm{SiO}_{2}$ on their surface in order to improve their wettability with molten aluminum were incorporated into the melt [1]. Magnesium was added to the melt in the final stage prior to pouring. The pouring temperature was maintained at $580-600{ }^{\circ} \mathrm{C}$ in semisolid state. Then the mould was left in air to cool down to room temperature. Finally the produced cast bars were turned to small disks to get the required specimens to be used in corrosion test (specimen dimensions were: $25 \mathrm{~mm}$ in diameter and $10 \mathrm{~mm}$ in thickness and each specimen has a hole of $8.5 \mathrm{~mm}$ in diameter.). The total surface area for each sample was $1920 \mathrm{~mm}^{2}$.

\subsection{Weight Loss Measurements}

For full immersion method the specimens were suspended in glass jar contains the corrodent solution (1.0M solution of $\mathrm{HCl}$ or $1.0 \mathrm{M}$ solution of $\mathrm{NaOH})$ using plastic string. The corrodent solution was exposed to atmospheric air and its temperature was maintained at $23-25{ }^{\circ} \mathrm{C}$. The weight loss rates were determined by removing specimens from test solutions at 30 minutes intervals with total testing time of 240 minutes. To avoid local crevice corrosion, the specimens were firstly ground with \#600 SiC abrasive paper, the specimens were then doubly rinsed under running water, cleaned in ethanol to remove any remaining debris, and to ensure complete dryness of the specimens, they were dried in oven at $70{ }^{\circ} \mathrm{C}$ for 20 minutes and then cooled to room temperature prior to weighing using electronic balance having $0.1 \mathrm{mg}$ accuracy. The specimens were subsequently returned to the testing solutions and the procedure repeated progressively for 240 minutes. Cumulative weight loss was established based on the original weight of each specimen. New similar specimens were used in $1.0 \mathrm{M} \mathrm{NaOH}$ solution to get a relative comparison of the corrosion resistance of the specimens in both acidic and alkaline solutions. The corroded surfaces were then examined using scanning electron microscope (SEM) (Quanta 200) equipped with Energy dispersive X-ray spectroscopy (EDS) (EDAX). 


\section{RESULTS AND DISCUSSIONS}

The presence of copper as alloying element in aluminum is essential component in formulating the high strength aging alloys, it has been reported that copper seriously diminishes the corrosion resistance of aluminum alloys although it [4-5]. Copper is dissolved in casting process in the matrix phase of the alloy and is concentrated into a variety of second phase particles. Predominant particles include $\mathrm{Mg}_{2} \mathrm{Si}, \mathrm{Al}_{5} \mathrm{Mg}_{8} \mathrm{Si}_{6} \mathrm{Cu}_{2}, \mathrm{Al}_{2} \mathrm{Cu}$ and $\mathrm{Al}_{2} \mathrm{CuMg}$ [4, 16-17]. Also, the formation of $\mathrm{Al}-\mathrm{Cu}-\mathrm{Mg}$ intermetallic particles promotes the cathodic reduction of oxygen and then accelerates corrosion process [17]. Consequently the passive films formed on the Al-Cu-Mg intermetallic particles were chemically different and less protective than those formed on the aluminum matrix [5,17]. Copper and magnesium-rich intermetallics strongly influenced the corrosion behavior of aluminum. According to Blanc et al. [17] the reactivity of $\mathrm{Cu}$ and $\mathrm{Mg}$ intermetallics can be described by a three-step process consisting of homogeneous dissolution, copper re-deposition followed by local dissolution of the surrounding matrix. Many other researchers have discussed the importance of intermetallic particles as initiation sites for corrosion [12,18-24].

Aluminum based composites tend to corrode in a localized manner; several studies on the corrosion of aluminum and its composites in chloride-containing solutions showed that the origin of localized attack depends highly on the alloy composition and microstructure (which is affected by the processing method). Possible mechanisms include: microgalvanic coupling between the matrix and reinforcement or between the matrix and intermetallics, failure of the protective oxide film due to micro-segregation of the alloying elements or micro-crevices at the matrix-reinforcement interface [13]. When the composites are fabricated by the melt route then degradation mechanism might take place, especially for light metals such as Mg. Also there is a possibility of degradation of $\mathrm{SiC}$ [8]; this is related to the potential attack of SiC by liquid aluminum and the subsequent degradation according to the following reactions [15]:

$$
\begin{aligned}
& 3 \mathrm{SiC}_{(\mathrm{s})}+4 \mathrm{Al}_{(\mathrm{l})} \rightarrow \mathrm{Al}_{4} \mathrm{C}_{3(\mathrm{~s})}+3 \mathrm{Si}_{(\mathrm{in} 1 \mathrm{Al})} \\
& \mathrm{Al}_{4} \mathrm{C}_{3(\mathrm{~s})}+12 \mathrm{H}_{2} \mathrm{O}_{(\mathrm{g})} \rightarrow 4 \mathrm{Al}(\mathrm{OH})_{3(\mathrm{~s})}+3 \mathrm{CH}_{4(\mathrm{~g})} \\
& \mathrm{Al}_{4} \mathrm{C}_{3(\mathrm{~s})}+18 \mathrm{H}_{2} \mathrm{O}_{(\mathrm{l})} \rightarrow 4 \mathrm{Al}(\mathrm{OH})_{3(\mathrm{~s})}+3 \mathrm{CO}_{2(\mathrm{~g})}+12 \mathrm{H}_{2}
\end{aligned}
$$


The intermetallic precipitates that may found during casting process are $\mathrm{Al}_{4} \mathrm{C}_{3}$ and free Si- type intermetallic, the contribution of such hard intermetallic precipitates is to increase corrosion rate in monolithic aluminum alloys and matrix composites [2, 8]. The chemical reaction of $\mathrm{Al}_{4} \mathrm{C}_{3}$ with water (even with moisture in the atmosphere at room temperature) and other environments such as $\mathrm{HCl}$ and $\mathrm{NaOH}$ is thermodynamically favorable and could be detrimental to the composites properties $[8,13]$.

Silicon dioxide $\left(\mathrm{SiO}_{2}\right)$ as it formed from reaction between aluminum and oxidized silicon carbide particles in $\mathrm{Al} / \mathrm{SiC}$ composites would have various beneficial effects [8]: i) abating processing costs, ii) preventing the formation of $\mathrm{Al}_{4} \mathrm{C}_{3}$ and iii) promoting in situ growth of thermodynamically stable phases $\left(\mathrm{MgO}, \mathrm{MgAl}_{2} \mathrm{O}_{4}\right)$ that may act as reinforcements, according to [8] the following reactions may take place:

$$
\begin{aligned}
& \mathrm{SiO}_{2(\mathrm{~s})}+2 \mathrm{Mg}_{(\mathrm{l})} \rightarrow 2 \mathrm{MgO}_{(\mathrm{s})}+\mathrm{Si}_{(\mathrm{in} 1 \mathrm{Al})} \\
& \mathrm{Mg}_{(\mathrm{l})}+2 \mathrm{Al}_{(\mathrm{l})}+2 \mathrm{SiO}_{2(\mathrm{~s})} \rightarrow \mathrm{MgAl}_{2} \mathrm{O}_{4(\mathrm{~s})}+2 \mathrm{Si}_{\text {(in } \mathrm{Al})} \\
& \left.4 \mathrm{Al}_{6} \mathrm{Si}_{2} \mathrm{O}_{13(\mathrm{~s})}+13 \mathrm{Mg}_{(\mathrm{l})}+2 \mathrm{Al}_{(\mathrm{l})} \rightarrow 13 \mathrm{MgAl}_{2} \mathrm{O}_{4(\mathrm{~s})}+8 \mathrm{Si} \text { (in } \mathrm{Al}\right)
\end{aligned}
$$

In addition to these reactions, the following chemical reaction between molten aluminum and $\mathrm{SiO}_{2}$ is also thermodynamically possible [8]:

$$
\frac{3}{2} \mathrm{SiO}_{2(\mathrm{~s})}+2 \mathrm{Al}_{(\mathrm{l})} \rightarrow 2 \mathrm{Al}_{2} \mathrm{O}_{3(\mathrm{~s})}+\frac{3}{2} \mathrm{Si}_{(\text {in } 1 \mathrm{Al})}
$$

Although the rejection of a certain amount of silicon into the alloy matrix is useful to prevent the formation of $\mathrm{Al}_{4} \mathrm{C}_{3}$, it may represent a potential problem. Reaction of $\mathrm{Si}$ in the alloy (or that formed as a by-product) with magnesium might produce $\mathrm{Mg}_{2} \mathrm{Si}$ during solidification of the alloy matrix in the composites. The intermetallic $\mathrm{Mg}_{2} \mathrm{Si}$ has been reported to be electrochemically active and may enhance localized corrosion [8]. On the other hand, high dislocation densities have been observed at the $\mathrm{Al}-\mathrm{SiC}$ matrix interfaces as a result of differential thermal contraction between $\mathrm{SiC}$ particles and the $\mathrm{Al}$ matrix [9]. Also the protruded $\mathrm{SiC}$ particles increase the surface area which becomes in contact with corroding solution and hence increase the susceptibility of the surface to be corroded. 
Figures 1 and 2 show the cumulative mass loss of different specimens in 1.0M HCl solution and $1.0 \mathrm{M} \mathrm{NaOH}$ solution, respectively. The non-uniformity and non-linearity of the plots suggest that the $\mathrm{Al}$ corrosion by $\mathrm{HCl}$ and $\mathrm{NaOH}$ environments is heterogeneous processes. In acidic and alkaline environments the heterogeneous process involving several phases: in the first phase the hard oxide film is damaged by corrodent and in the second phase with increased exposure time a steady state will be reached as the corrodent reaches the oxide-free matrix; hence it allows equilibrium in the kinetics of dissolution of the outer porous layer and build-up of an inner compact layer to be reached after an interval of time. Pitting is the predominant form of localized corrosion in this step [6, 9, and 16]. Similar observations have been also noticed in the present study for corrosion of $\mathrm{Al}$ in $\mathrm{NaOH}$ solution.
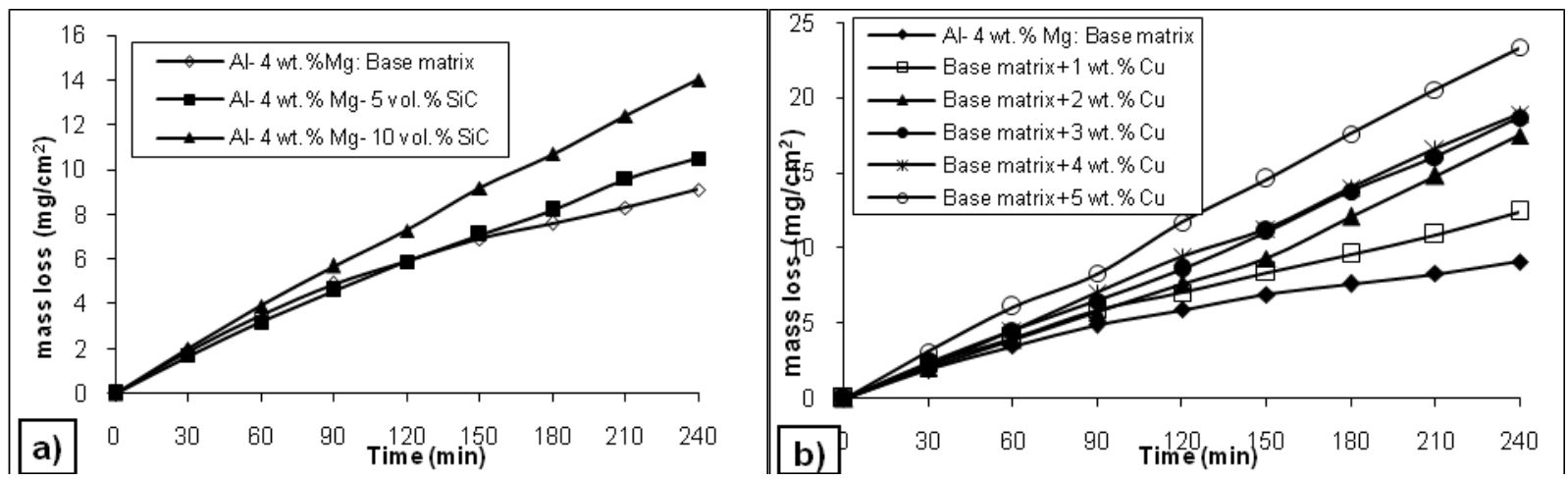

Fig. 1 Cumulative mass loss of: a) Al-4wt.\%Mg-Cu alloys, and b) Al-4wt.\%Mg-SiC composites in 1.0M HCl
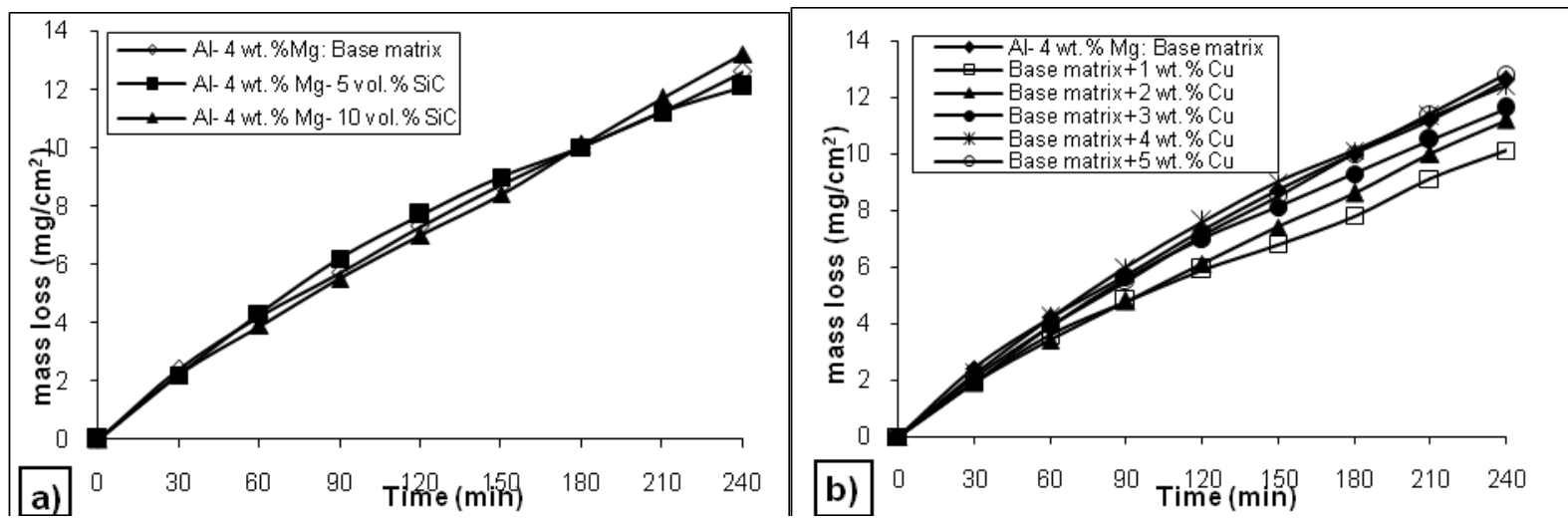

Fig. 2 Cumulative mass loss of: a) Al-4wt.\%Mg-Cu alloys, and b) Al-4wt.\%Mg-SiC composites in 1.0M NaOH 


\subsection{Thermodynamics Of Corrosion}

The dissolution of Al- based alloys and composites have shown stronger affection by acidic solution of $\mathrm{HCl}$ compared to alkaline solution of $\mathrm{NaOH}$. To compare the effect of dissolution kinetics of Al-based alloys/composites in alkaline and acidic solutions the first order Arrhenius equation:

$$
K=\mathrm{A} \cdot \exp \left(-\frac{\mathrm{E}_{\mathrm{a}}}{\mathrm{RT}}\right)
$$

Where $E_{a}$ is the apparent activation energy which depends on type of material, corrodent and temperature, $\mathrm{R}$ is the ideal gas constant $\left(8.314 \mathrm{~J} \cdot \mathrm{mol}^{-1} \cdot \mathrm{K}^{-1}\right)$, and $\mathrm{T}$ is absolute temperature. In its original form the pre-exponential factor $\mathrm{A}$ and the activation energy $\mathrm{E}_{\mathrm{a}}$ are considered to be temperature-independent. The rate constants can be calculated according to the following equation [13]:

$$
\mathrm{K}=\frac{1}{\mathrm{t}} \ln \left(\frac{w_{i}}{w_{f}}\right)
$$

$\mathrm{w}_{\mathrm{i}}$ represents the initial weight of specimen and $\mathrm{w}_{\mathrm{f}}$ represents the final weight of specimen after immersion in corrodent solution for 240 minutes and t is time in minutes (i.e. 240 minutes). The half-time $\left(\mathrm{t}_{1 / 2}\right)$ was calculated from the first order Arrhenius equation [13]:

$$
t_{1 / 2}=\frac{0.693}{K}
$$

When $\ln \left(\mathrm{w}_{\mathrm{i}}-\Delta \mathrm{w}\right)$ is plotted against time a linear plot is obtained which confirms first order Arrhenius equation as shown in Fig. 3. Arrhenius first order equation was used to estimate the kinetic data like rate constant $(\mathrm{K})$ and half time $\left(\mathrm{t}_{1 / 2}\right)$ as shown in Table 1. Fig. 4 has been plotted to manifest the relative corrosion thermodynamics data in Table 1. Fig.4 shows the rate constant and half-time $\left(\mathrm{t}_{1 / 2}\right)$ for different alloys and composites in $1.0 \mathrm{M} \mathrm{HCl}$ and $1.0 \mathrm{M} \mathrm{NaOH}$ solutions, respectively. The first observation from these figures indicates that the average corrosion rates of Al-based materials in alkaline environment is lower than corrosion rate in acidic environment, however, severe damaged is resulted from the acidic environments. Also, from these figures one can observe that the rate constant varies considerably for Al-based specimens used in $1.0 \mathrm{M} \mathrm{HCl}$ solution compared to the specimens used in $1.0 \mathrm{M} \mathrm{NaOH}$ ( in $1.0 \mathrm{M}$ $\mathrm{HCl}$ rate constant range from $95.98 \times 10^{-4}$ for $\mathrm{Al}-4 \mathrm{wt} . \% \mathrm{Mg}$ to $250.63 \times 10^{-4}\left(\mathrm{~min}^{-1}\right)$ for $\mathrm{Al}-$ 4wt.\%Mg-5wt.\%Cu-10vol\%SiC which can be compared to the corresponding values in $1.0 \mathrm{M}$ 
$\mathrm{NaOH}$ as they ranged from $91.63 \times 10^{-4}$ for $\mathrm{Al}-4 \mathrm{wt} . \% \mathrm{Mg}$ to $120.65 \times 10^{-4}$ for $\mathrm{Al}-4 \mathrm{wt} . \% \mathrm{Mg}-$ $5 w t . \% C u-10 v o l \% S i C)$. Hence it is clear that the acidic solution has stronger effect on the $\mathrm{Al}-$ based surfaces when compared to $\mathrm{NaOH}$ solutions.
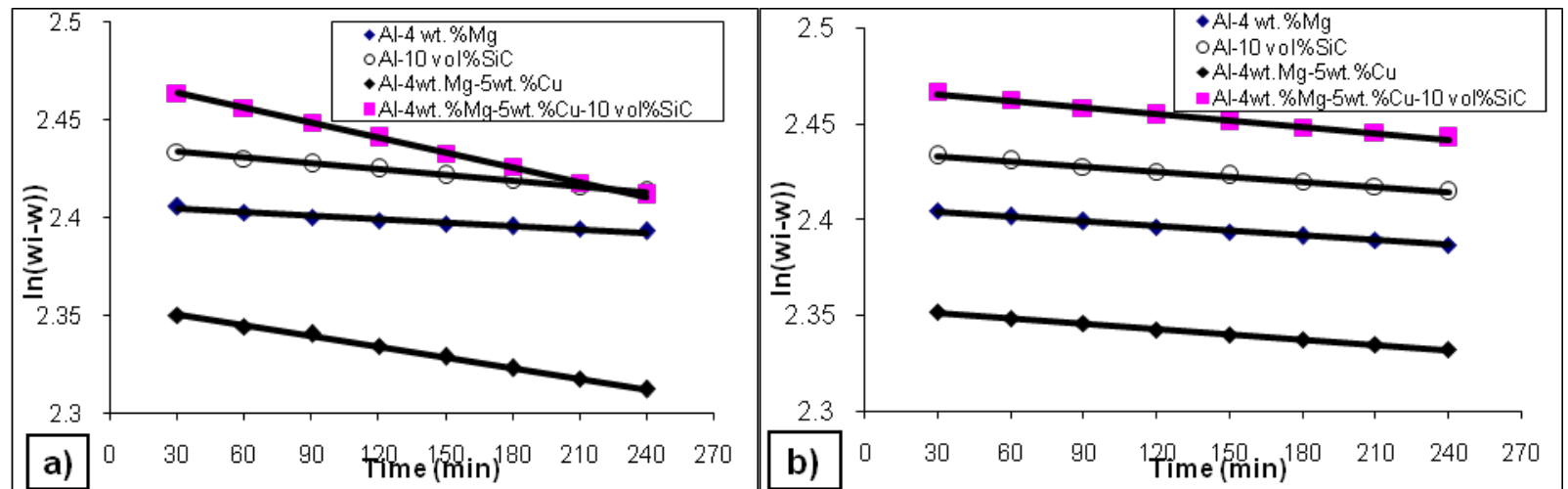

Fig. 3 Variation of $\log \left(w_{i}-\Delta w\right)$ with time for different samples in: a) 1.0M HCl solution, and b) 1.0M NaOH solution.

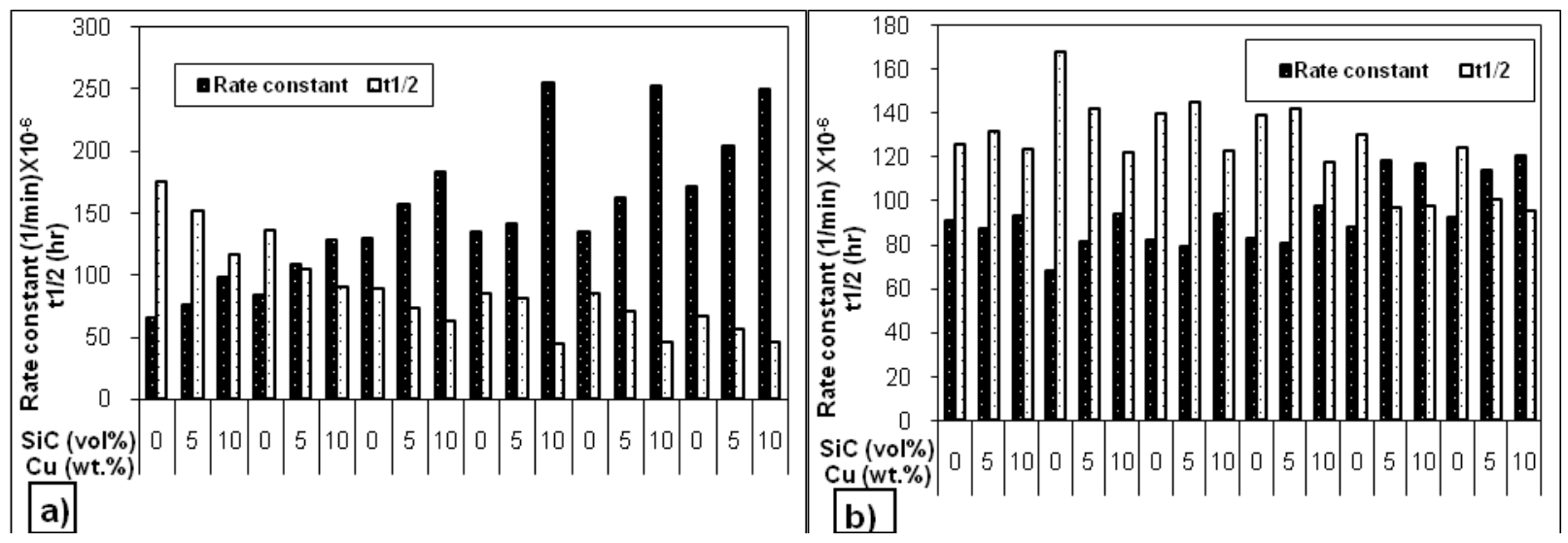

Fig. 4 Rate constant (K) and half time (t 1/2) for different alloys and composites in: a) 1.0M HCl solution, and b) $1.0 \mathrm{M} \mathrm{NaOH}$ solution 
Table 1 Thermodynamic data of different alloys and composite specimens used in this study

\begin{tabular}{|c|c|c|c|c|c|c|}
\hline \multirow[b]{2}{*}{ Sample No. } & \multirow[b]{2}{*}{$\begin{array}{c}\mathrm{Cu} \\
\text { (wt.\%) }\end{array}$} & \multirow[b]{2}{*}{$\begin{array}{c}\text { SiC } \\
\text { (vol\%) }\end{array}$} & \multicolumn{2}{|c|}{ in $1.0 \mathrm{M} \mathrm{HCl}$} & \multicolumn{2}{|c|}{ in $1.0 \mathrm{M} \mathrm{NaOH}$} \\
\hline & & & $K\left(X 10^{-6}\right)$ & t1/2 (hr) & $K\left(X 10^{-6}\right)$ & t1/2 (hr) \\
\hline 1 & 0 & 0 & 65.979 & 175.056 & 91.636 & 126.042 \\
\hline 2 & 0 & 5 & 75.879 & 152.217 & 87.564 & 131.904 \\
\hline 3 & 0 & 10 & 99.089 & 116.562 & 93.363 & 123.711 \\
\hline 4 & 1 & 0 & 84.411 & 136.831 & 68.624 & 168.308 \\
\hline 5 & 1 & 5 & 109.317 & 105.656 & 81.351 & 141.978 \\
\hline 6 & 1 & 10 & 128.060 & 90.192 & 94.562 & 122.142 \\
\hline 7 & 2 & 0 & 129.828 & 88.964 & 82.622 & 139.793 \\
\hline 8 & 2 & 5 & 157.082 & 73.528 & 79.662 & 144.987 \\
\hline 9 & 2 & 10 & 184.172 & 62.713 & 93.947 & 122.942 \\
\hline 10 & 3 & 0 & 134.560 & 85.836 & 82.957 & 139.228 \\
\hline 11 & 3 & 5 & 141.363 & 81.704 & 80.997 & 142.599 \\
\hline 12 & 3 & 10 & 255.595 & 45.189 & 97.746 & 118.1638 \\
\hline 13 & 4 & 0 & 135.549 & 85.209 & 88.432 & 130.609 \\
\hline 14 & 4 & 5 & 162.062 & 71.269 & 118.966 & 97.086 \\
\hline 15 & 4 & 10 & 252.646 & 45.716 & 117.499 & 98.298 \\
\hline 16 & 5 & 0 & 171.297 & 67.427 & 92.827 & 124.425 \\
\hline 17 & 5 & 5 & 205.143 & 56.302 & 114.287 & 101.061 \\
\hline 18 & 5 & 10 & 250.630 & 46.084 & 120.648 & 95.733 \\
\hline
\end{tabular}

\subsection{Surface Characterization}

The specimens were exposed to corrodent solutions for 240 minutes before they examined using scanning electron microscope (SEM) and energy dispersive X-ray (EDS). Fig. 5 shows photographs of the surface of some corroded specimens investigated in this work. Visual inspection with the aid of this figure shows that the $\mathrm{HCl}$ solution has stronger effect on the surface of Al-based materials than the $\mathrm{NaOH}$ solution. However, such kind of subjective judgment is rather important, but at least it gives us a feeling of what is happening in the corrosion test. During the testing period and especially in the initial periods, pitting corrosion is the dominant type of corrosion followed by formation of white and light-gray powders on the specimen surfaces. The amount of that powder was observed significantly in the $1.0 \mathrm{M} \mathrm{NaOH}$ solution. However, polished surfaces were obtained after the termination of the corrosion test in 1.0M $\mathrm{NaOH}$ as shown in Fig. 5. In $1.0 \mathrm{M} \mathrm{HCl}$ solution it was observed continuous pitting corrosion of surface with decreasing corrosion rate due to the etching effect of acidic solutions. 
The etched layer forms some anti-corrosion film which enhances corrosion resistance of interior matrix [5].
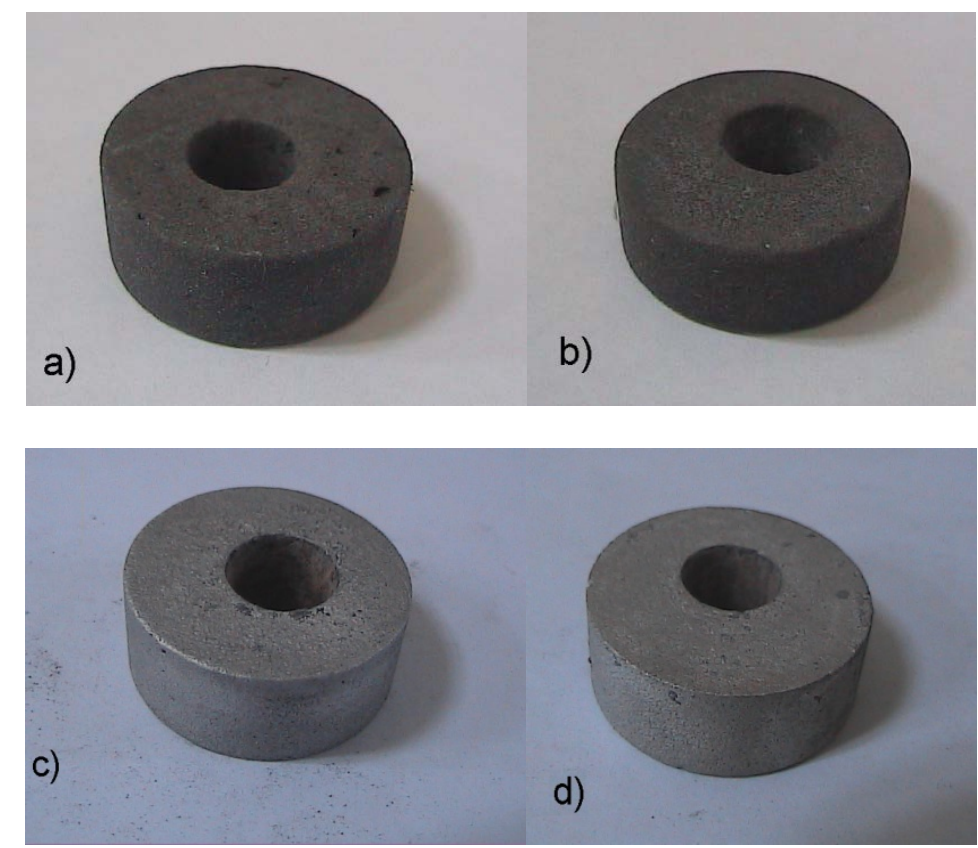

Fig. 5 Photos showing corroded surface of: a) Al-4wt.\%Mg-4wt.\%Cu alloy in 1.0M HCl; b) Al4wt.\%Mg-10vol\%SiC composite in 1.0M HCl; c) Al-4wt.\%Mg-4wt.\%Cu alloy in 1.0M NaOH; d) $\mathrm{Al}-4 \mathrm{wt} . \% \mathrm{Mg}-10 \mathrm{vol} \% \mathrm{SiC}$ composite in $1.0 \mathrm{M} \mathrm{NaOH}$

The second parts of Fig's 6-11 show the EDS spectrum of the corroded region, revealing the presence of the different elements which form the alloy/composite. The presence of silicon for example is due to the natural formation in the alloy and/or composite in trace amounts or may reject from reactions (5) and (6). On the other hand, the presence of oxygen is attributed to hydrated aluminum oxide and possibly to the presence of $\mathrm{Mg}(\mathrm{OH})_{2}$ [8]. The EDS analysis of some $\mathrm{Al}-4 \mathrm{wt} . \% \mathrm{Mg}-\mathrm{Cu}$ alloys shows small amounts of copper in the corroded surfaces although it was added on predetermined quantities (for example 4wt.\% in Fig.8 ). The EDS spectra indicate that there was only a very slight enrichment of copper in the corroded area as compared to the uncorroded surface. However, a very significant enrichment of $\mathrm{Cu}$ was observed locally in the form of copper-rich or possibly pure copper particles. It should also be noted that no coppercontaining particles were observed on uncorroded areas of the sample. This can be attributed to the stronger electrochemical behavior of copper which makes it easily to dissolute from the 
matrix and rejected into the electrolyte solution. EDS analysis indicates that the bright spots are copper enriched particles [17-20]. For example, Fig's 8, 10 and 11 show such copper-enriched spots indicated by white arrows. Hard attack was observed in the $\mathrm{Al} / \mathrm{SiC}$ composites as appear in SEM analysis by darker spots due to hard etching of the SiC particles and their surrounding matrix in both acidic and alkaline solutions, but generally the harder attack was observed in acidic solution.

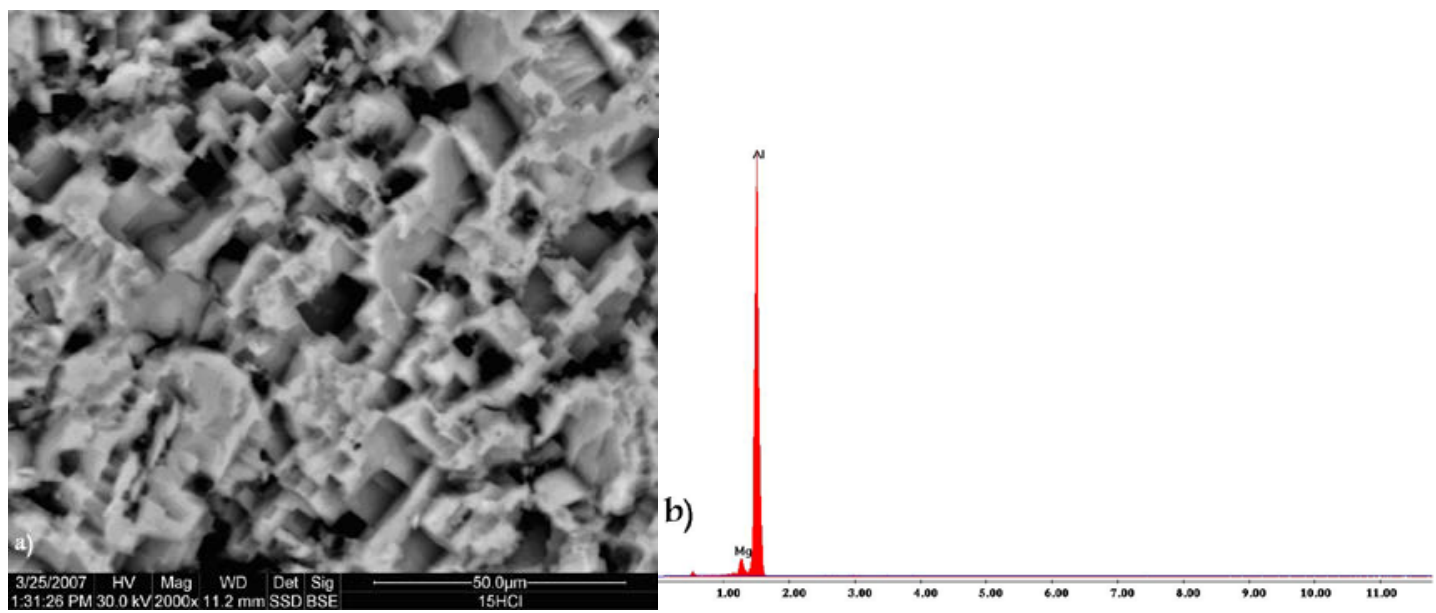

Fig. 6 a) SEM micrograph of corroded surface of $\mathrm{Al}-4 \mathrm{wt} . \% \mathrm{Mg}$ alloy in $1.0 \mathrm{M} \mathrm{HCl}$ solution after 240 minutes, and b) Corresponding EDS analysis showing the attacked surface and chemical composition of corroded surface
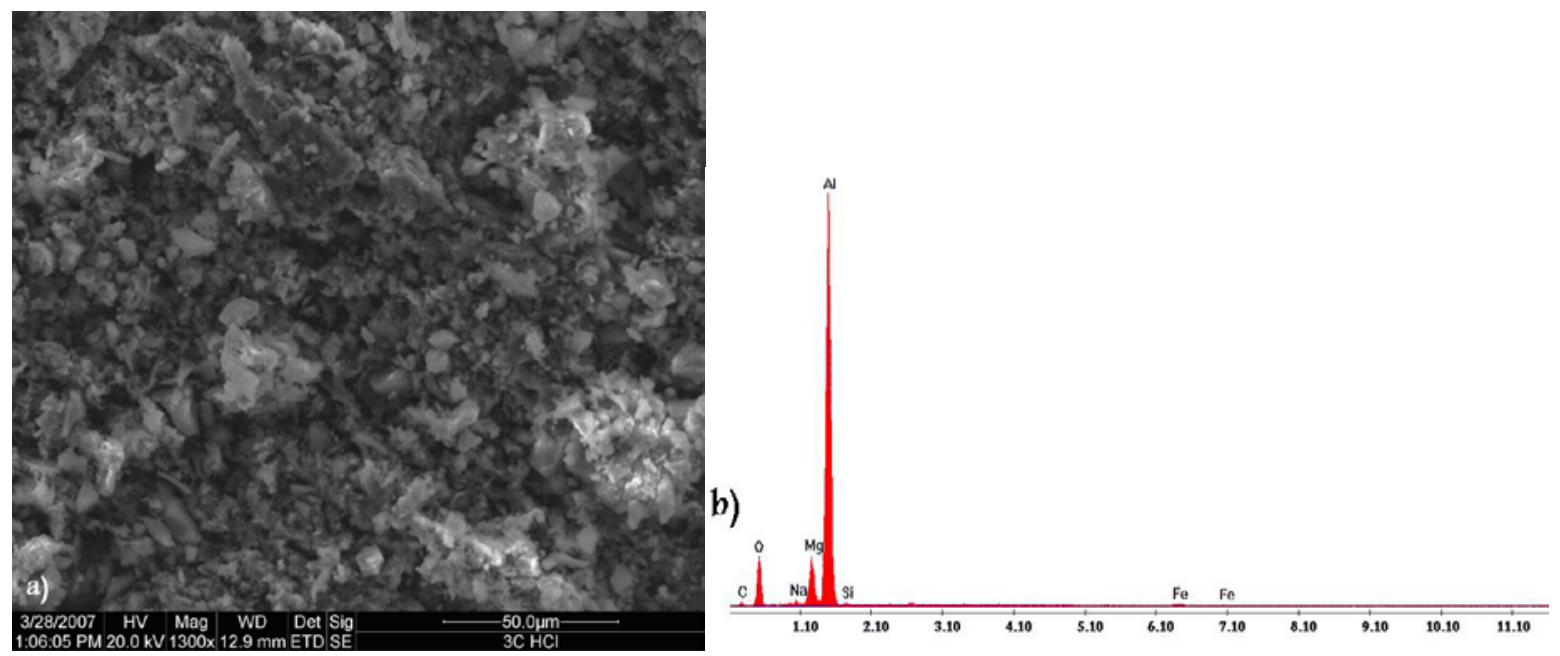

Fig. 7 a) SEM micrograph of corroded surface of Al-4wt.\%Mg-10 vol.\%SiC composite in 1.0M $\mathrm{HCl}$ solution after 240 minutes, and b) Corresponding EDS analysis showing the attacked surface and chemical composition of corroded surface. 

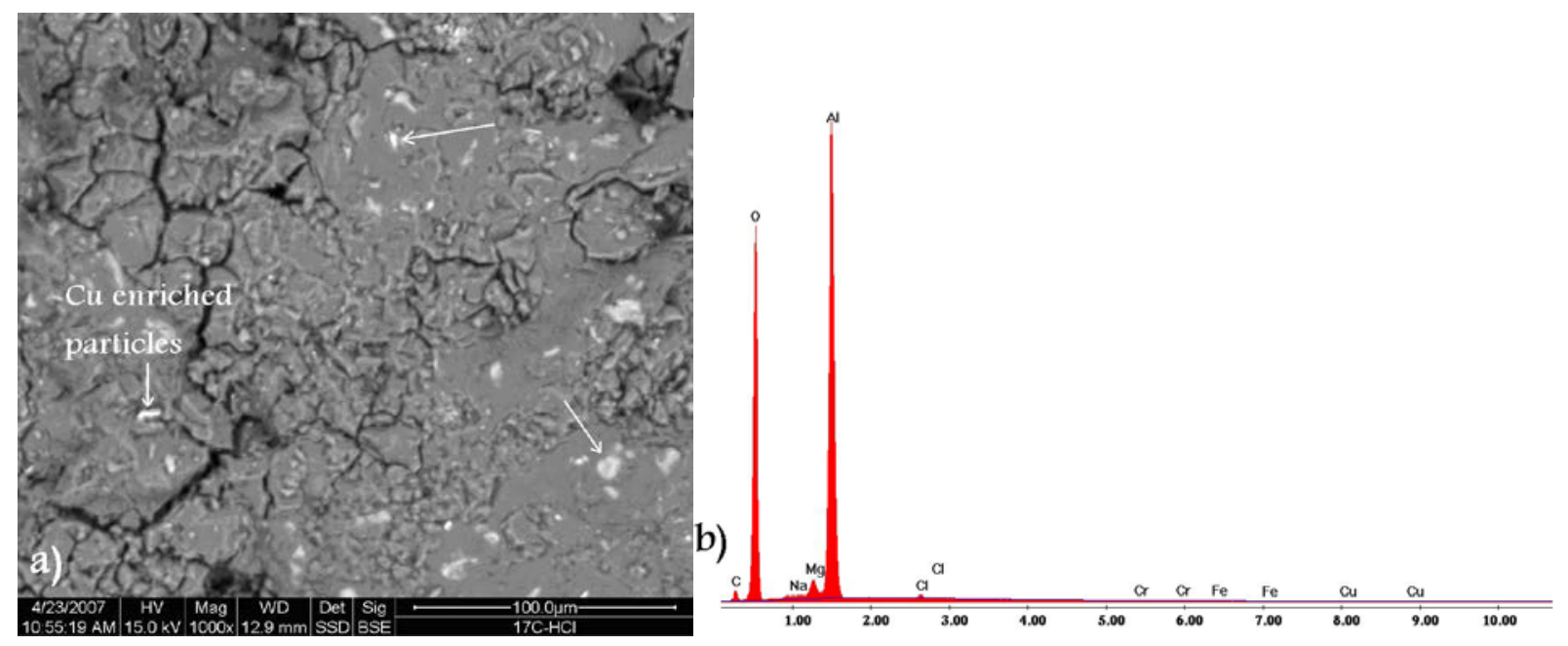

Fig. 8 a) SEM micrograph of corroded surface of Al-4wt.\%Mg-4 wt.\%Cu alloy in 1.0M HCl solution after 240 minutes, and b) Corresponding EDS analysis showing the attacked surface and chemical composition of corroded surface.

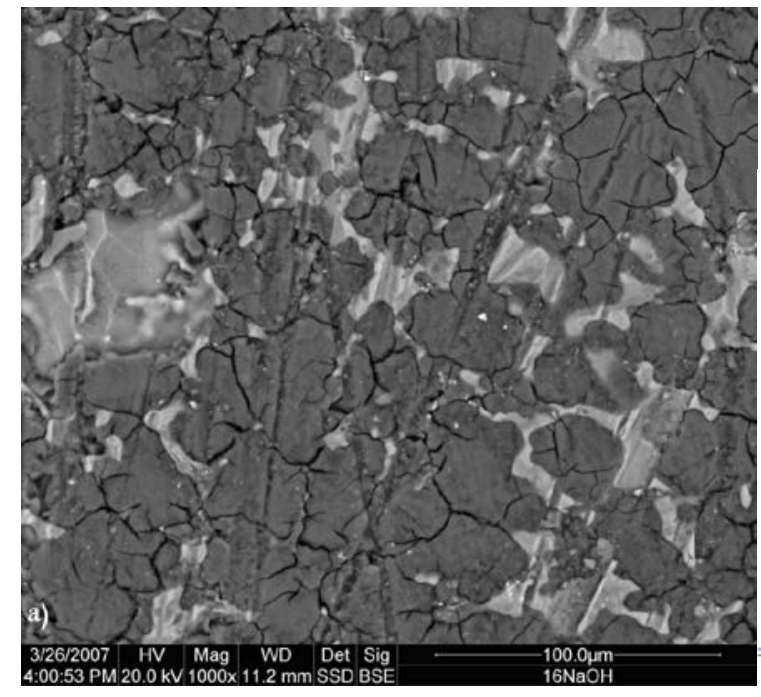

b)

Fig. 9 a) SEM micrograph of corroded surface of Al-4wt.\%Mg alloy in 1.0M NaOH solution after 240 minutes, and b) Corresponding EDS analysis showing the attacked surface and chemical composition of corroded surface. 

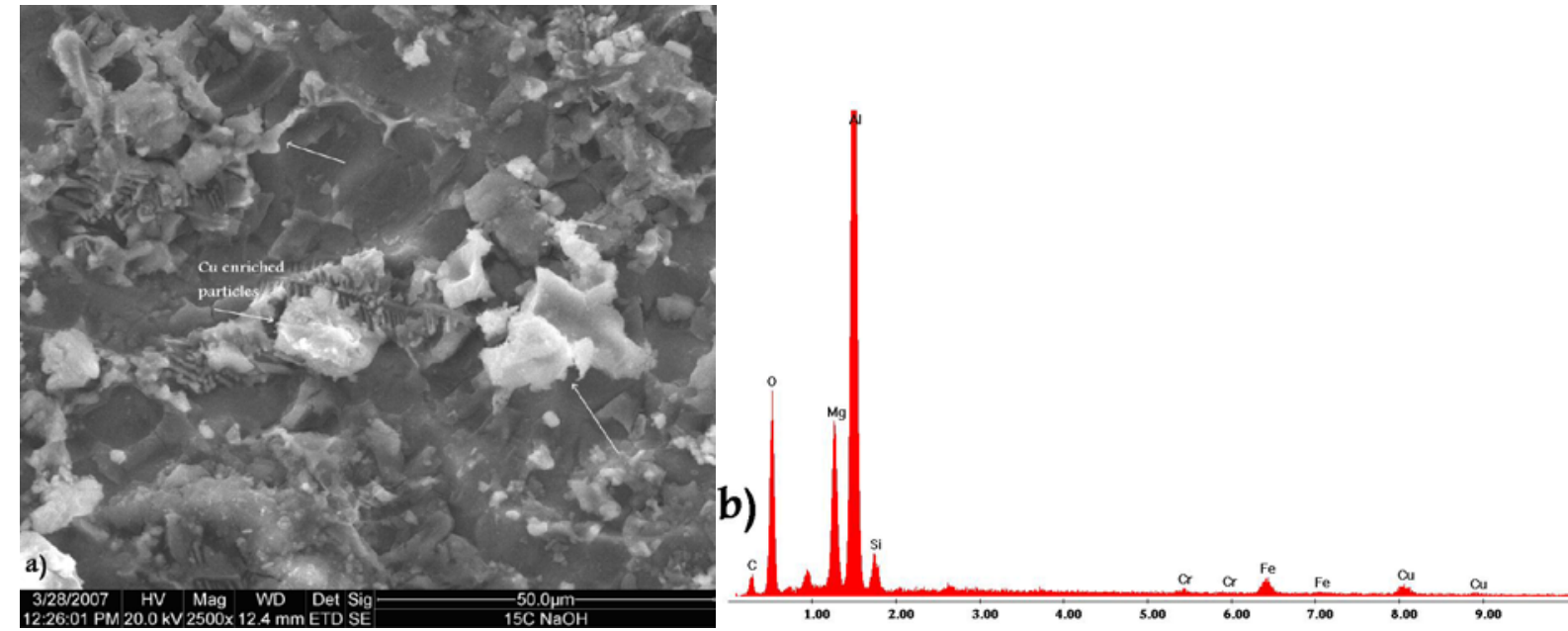

Fig. 10 a) SEM micrograph of corroded surface of Al-4wt.\%Mg-4 wt.\%Cu alloy in 1.0M $\mathrm{NaOH}$ solution after 240 minutes, and b) Corresponding EDS analysis showing the attacked surface and chemical composition of corroded surface.
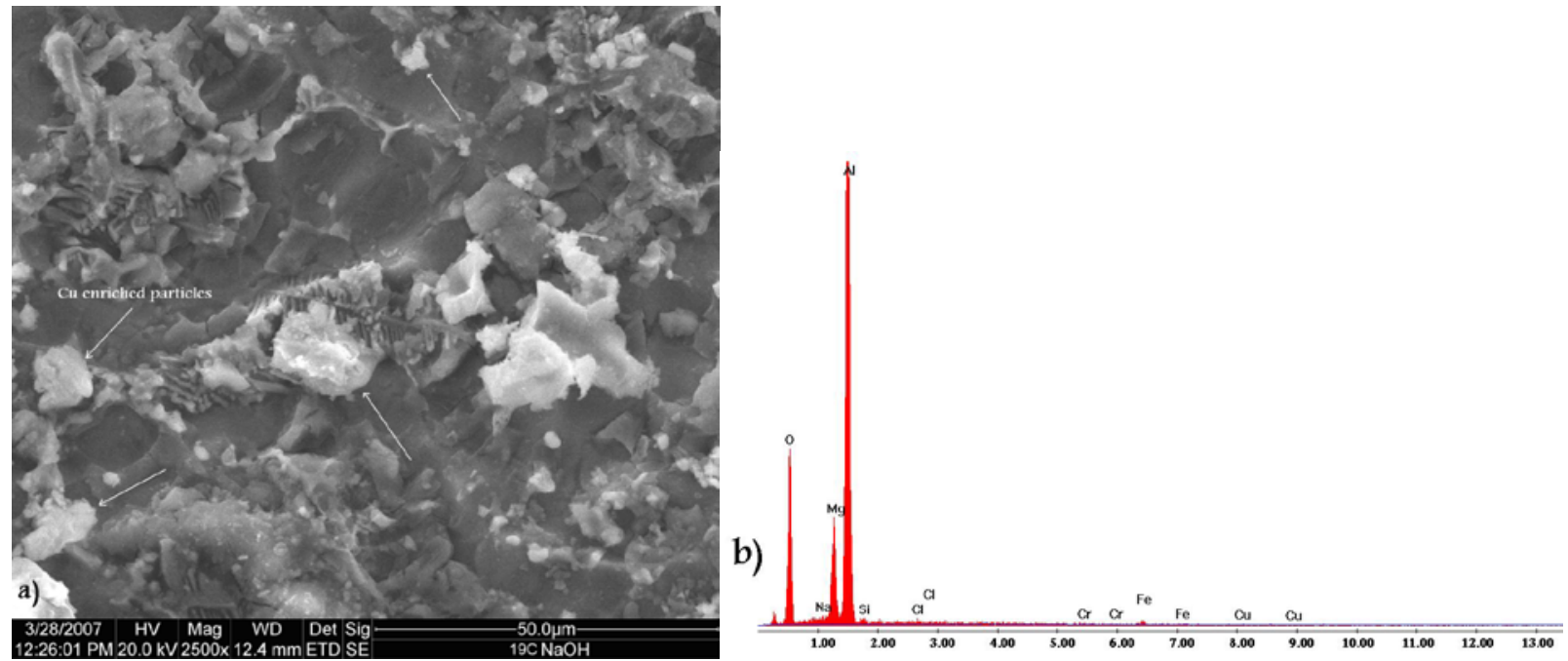

Fig. 11 a) SEM micrograph of corroded surface of Al-4wt.\%Mg-4 wt.\%Cu-10 vol\%SiC composite in 1.0M NaOH solution after 240 minutes, and b) Corresponding EDS analysis showing the attacked surface and chemical composition of corroded surface.

\section{CONCLUSION}

The major type of corrosion of aluminum-based materials in $\mathrm{HCl}$ and $\mathrm{NaOH}$ solutions is pitting corrosion. In the present work, it was found that the addition of copper and silicon carbide into 
Al-4 wt.\%Mg alloy tend to diminish the excellent corrosion resistance of pure aluminum in both acidic and alkaline media. The addition of $\mathrm{SiC}$ particles will also diminish the corrosion resistance of $\mathrm{Al}-4 \mathrm{wt} . \% \mathrm{Mg}$ alloy since that it is difficult to achieve very good bond-ability between ceramic and metal. On the other hand, during corrosion tests in extremely alkaline or acid solutions, $\mathrm{Cu}$ surface enrichment likely occurs by particle dissolution and de-alloying and possible de-alloying of the matrix phase. It was found that both Al-based alloys and their associated composites have fewer tendencies to corrode in $\mathrm{NaOH}$ compared to $\mathrm{HCl}$ environment. SEM analysis shows that the corrosion effect on the silicon carbide containing composites is more sever compared to corresponding $\mathrm{Al}-4 \mathrm{wt} . \% \mathrm{Mg}-\mathrm{Cu}$ alloys. When conducting EDS analysis the absence of copper on the corroded surfaces is attributed to the high chemical activity of copper either by formation of the hard intermetallic particles which are usually very active or by dissolution in corrodent.

\section{ACKNOWLEDGEMENTS}

The authors gratefully acknowledge the assistance of the committee of scientific research/ Jordan University of Science and Technology for its support of this research (grant No. 29/2007). The authors would like also to gratefully acknowledge the use of Machine shop and the laboratory facilities at Jordan University of Science and Technology, Irbid, Jordan

\section{REFERENCES}

1. Ahlatci H, Kocer $\mathrm{T}$, Candan E, Cimenoglu $\mathrm{H}$. Wear behaviour of $\mathrm{Al} /\left(\mathrm{Al}_{2} \mathrm{O}_{3 \mathrm{P}}+\mathrm{SiC}_{\mathrm{P}}\right)$ hybrid composites. Tribology international 2006; 39: 213-220.

2. Hassan AM, Tashtoush GM, Alkhalil JA. The effect of graphite and/or silicon carbide addition on the hardness and surface roughness of Al- 4 wt.\%Mg alloy. Composite materials 2007; 41(4): 453-465.

3. Gouveia-Caridade C, Pereira MIS. Brett CMA. Electrochemical noise and impedance study of aluminum in weakly acid chloride solution. Electrochimica Acta 2004; 49: 785793.

4. Kiourtsidis GE, Skolianos SM. Pitting corrosion of artificially aged T6 AA2024/SiCp 
composites in 3.5wt.\% $\mathrm{NaCl}$ aqueous solution. Corrosion Science. Corrosion Science 2007; 49: 2711-2725.

5. Szklarska-Smialowska Z. Pitting corrosion of aluminum. Corrosion Science 1999; 41 : 1743-1767.

6. Rushing JC, Edwards M. Effect of aluminum solids and chlorine on cold water pitting of copper. Corrosion Science 2004; 46: 3069-3088.

7. Escalera-Lozano R, Gutiérrez CA, Pech-Canul MA, Pech-Canul MI. Corrosion characteristics of hybrid $\mathrm{Al} / \mathrm{SiCp} / \mathrm{MgAl}_{2} \mathrm{O}_{4}$ composites fabricated with fly ash and recycled aluminum. Materials Characterization 2006; 58(10): 953-960.

8. Ahmad Z, Abdul Aleem BJ. Degradation of aluminum metal matrix composites in salt water and its control. Materials and Design 2002; 23: 173-180

9. Ramachandra M, Radhakrishna K. Sliding wear, slurry erosive wear, and corrosive wear of aluminum/SiC composite. Materials science- Poland 2006; 24 (2/1):334-349.

10. Candan S. and Bilgic E. Corrosion behavior of Al-60vol.\%SiC $\mathrm{P}_{\mathrm{P}}$ composites in $\mathrm{NaCl}$, Materials letters 2004; 58: 2787-2790.

11. Sennur Candan. An investigation on corrosion behaviour of pressure infiltrated $\mathrm{Al}-\mathrm{Mg}$ alloy/SiC ${ }_{\mathrm{p}}$ composites. Corrosion Science 2009, 51(6): 1392-1398.

12. Sennur Candan. Effect of SiC particle size on corrosion behavior of pressure infiltrated $\mathrm{Al}$ matrix composites in a $\mathrm{NaCl}$ solution. Materials Letters 58 (2004) 3601 - 3605.

13. Abiola OK, Oforka NC, Angaye SS. Corrosion behavior of aluminum in hydrochloric acid (HCl) solution containing mercaptoacetic acid. Materials Letters 2004; 58: 3461-3466

14. Oguzie EE, Okolue BN, Ebenso EE, Onuoha GN, Onuchukwu AI. Evaluation of the inhibitory effect of methylene blue dye on the corrosion of aluminum in hydrochloric acid. Materials Chemistry and Physics 2004; 87:394-401.

15. Lunarska E, Chernyayeva O. Effect of corrosion inhibitors on hydrogen uptake by Al from $\mathrm{NaOH}$ solution. International Journal of Hydrogen Energy 2006; 31: 285 - 293.

16. Liu Z, Chong PH, Butt AN, Skeldon P, Thompson GE. Corrosion mechanism of lasermelted AA 2014 and AA 2024 alloys. Applied Surface Science 2005; 247: 294-299.

17. Blanc C, Freulon A, Lafont MC, Kihn Y, Mankowski G. Modelling the corrosion behavior of $\mathrm{Al}_{2} \mathrm{CuMg}$ coarse particles in copper-rich aluminum alloys. Corrosion Science 2006; 48: 3838-3851. 
18. Hintze PE, Calle LM. Electrochemical properties and corrosion protection of organosilane self-assembled monolayers on aluminum 2024-T3. Electrochimica Acta 2006; 51: 17611766.

19. Bakos I, Szabo S. Corrosion behavior of aluminum in copper containing environment. Corrosion Science 2008; 50: 200-205.

20. Svenningsen G, Larsen M H, Nordlien JH, Nisancioglu K. Effect of high temperature heat treatment on intergranular corrosion of $\mathrm{AlMgSi}(\mathrm{Cu})$ model alloy. Corrosion Science 2006; 48: 258-272.

21. Andrews A, Herrmann M, Sephton M, Machio C, Michaelis A. Electrochemical corrosion of solid and liquid phase sintered silicon carbide in acidic and alkaline environments. Journal of the European Ceramic Society 2007; 27: 2127-2135.

22. Afseth A, Nordlien JH, Scamans GM, Nisancioglu K. Filiform corrosion of binary aluminum model alloys. Corrosion Science 2002; 44: 2529-2542

23. Liu ZS, Huang GS, Gua MY. Effect of hydrolysis of AIN particulates on the corrosion behavior of Al/AlNp composites. Materials Chemistry and Physics 2006; 99: 75-79.

24. Branzoi V, Golgovici F, Branzoi F. Aluminium corrosion in hydrochloric acid solutions and the effect of some organic inhibitors. Materials Chemistry and Physics 2002; 78: 122131. 